\title{
A research framework of supply chain management in ready made garments industry of Bangladesh
}

\author{
Md. Farhan Shahriar ${ }^{1}$, Bishwajit Banik Pathik ${ }^{2}$, Md. Mamun Habib ${ }^{3}$ \\ ${ }^{1}$ Customer Services, Avery Dennison Bangladesh, Dhaka, Bangladesh \\ ${ }^{2}$ Dept. of Electrical \& Electronic Engineering, American International University-Bangladesh (AIUB), Dhaka, Bangladesh \\ ${ }^{3}$ School of Quantitative Sciences, Universiti Utara Malaysia (UUM), Kuala Lumpur, Malaysia
}

\section{Email address:}

titaskhanbd@gmail.com (Md. F. Shahriar), bishwajit.b.pathik@gmail.com (B. B. Pathik), md.mamun@uum.edu.my (Md. M. Habib)

\section{To cite this article:}

Md. Farhan Shahriar, Bishwajit Banik Pathik, Md. Mamun Habib. A Research Framework of Supply Chain Management in Ready Made Garments Industry of Bangladesh. International Journal of Business and Economics Research. Special Issue: Supply Chain Management: Its Theory and Applications. Vol. 3, No. 6-1, 2014, pp. 38-44. doi: 10.11648/j.ijber.s.2014030601.16

\begin{abstract}
This exploratory study addresses a conceptual supply chain management (SCM) model for ready-made garments (RMG) industry of Bangladesh. As different parties i.e. the suppliers, manufacturers, buyers etc. are involved in different phases of supply chain of this industry, every stage (procurement, manufacturing, replenishment, customer order) is conflicting with its next stage with the goals and objectives. In this conceptual model, attempts have been taken to create the layout and design of the procurement of raw materials, work-in-process, inventory and finished goods from various sources to the ultimate consumer in this garment business. This framework provides the opportunity to integrate and optimize the supply chain process of RMG industry of Bangladesh. The proposed conceptual framework for the RMG industry provides a novel approach for decision makers of supply chain components to review and appraise the performance toward fulfillment of ultimate goals, i.e. producing high-quality garments product, and reducing the wastage of human labor, time and money.
\end{abstract}

Keywords: Supply Chain Management, SCM Model for RMG, Ready-Made Garments (RMG), Supply Chain (SC)

\section{Introduction}

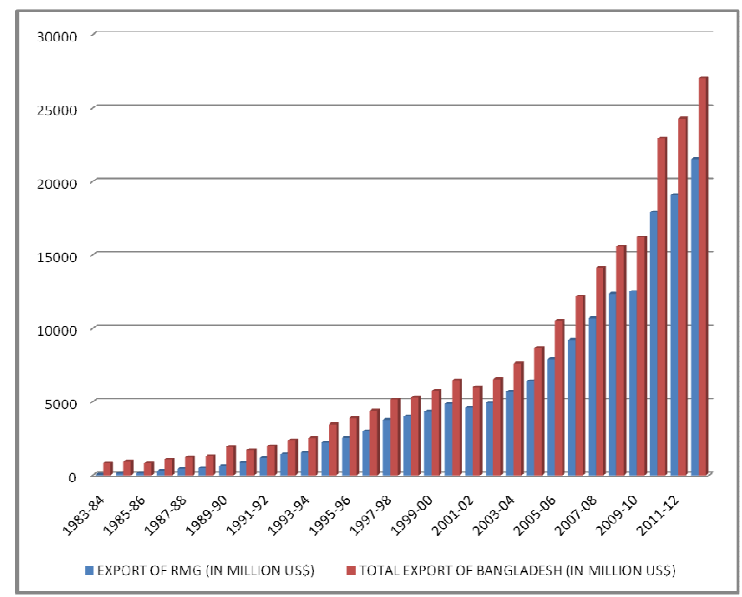

Figure 1. Export of RMG from Bangladesh (1983-2012) [1]

Bangladesh has been the one of the biggest export trade country of RMG and Apparel in the world market. This industry started in Bangladesh at the late 1970s, expanded heavily in the 1980s and boomed in the 1990s. The quick expansion of this industry was possible because of the use of less complicated technology, cheap labor, easy to operate sewing machines. If look below charts which represents the picture of export of RMG in comparative total export from Bangladesh.

Supply chain management systems help in reducing inventories, operational costs, compress order cycle time, enhance asset productivity as well as increase the companies' responsiveness to the market. Besides from these benefits, the apparel industry is able to achieve quick response through efficient supply chain management practices. Quick response is a concept pertaining to the collaboration and sharing or information among manufacturers, suppliers and distributors, allowing them to respond more rapidly to the needs of the customers. [2]

From this above chart find that total RMG export from Bangladesh, starting from 1984 to 2013. We can easily understand from this chart that how RMG sector contribute in Bangladesh economy. 


\section{Literature Review}

\subsection{Supply Chain Management}

A supply chain is a system of organizations, people, technology, activities, information and resources involved in moving a product or service from supplier to customer. Supply chain activities transform natural resources, raw materials and components into a finished product that is delivered to the end customer

The supply chain process for manufacturing and service industries started with suppliers, manufacturers, distributors, retailers, customers and suppliers, service providers, customers and end with consumers respectively. [10] The customers are the most vital focal point of the supply chain, since the primary purpose of the existence of any supply chain is to directly or indirectly satisfy customer needs.

In every manufacturing organization, for their working purpose they follow the basic supply chain. The following diagram is the basic supply chain for manufacturing organizations.

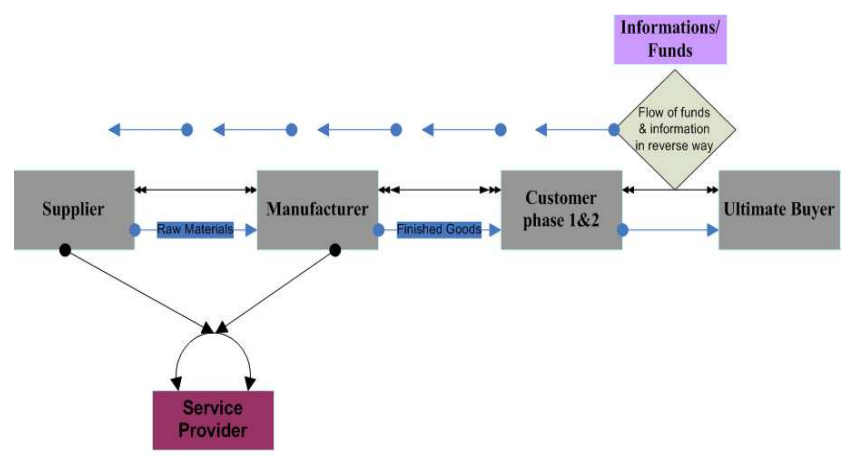

Figure 2. Basic Supply Chain [12]

The basic supply chain of readymade garment industry in Bangladesh are involves supplier, manufacturer, ultimate buyer and service provider.

\subsubsection{Supplier}

Fabrics, Accessories, Packaging producers are defined as supplier in garments industry. All the fabric items can be sourced from around the world but most of the time accessories and packaging item procure locally.

\subsubsection{Company}

Garments manufacturer or factories are defined as company. If we think about in Bangladesh perspective all the garments factories are working as a company.

(a) Customer Phase 1: Merchandise organization or buying house. In fact, all the merchandise organization and buying house working as a middleman between buyer and garments factories and for this service, they earn commission.

(b) Customer Phase 2: Retail Branding Owner (RBO)-H\&M, M\&S, Tesco etc. All the garments brands are in this phase. They are the main buyer and acted as a customer and they merchandise all the garments and distribute it through DC to available for consumers.

\subsubsection{Ultimate Buyer}

Consumer (who buys the product for ultimate use) is the most vital point for value chain in garments industry. All the works have been done for meeting the consumer needs in the

In this supply chain, there is another part that provides the service \& worked as helping hand for the manufacturing organization.

\subsubsection{Service Provider}

Bank, washing centers, printing centers are the service provider.. The entire service providers also act as a vital part in the value chain. Because all the banks are related with LC, export-import process, washing plants use for washing the garments, all the printing centers works for printing design or logo label in the garments.

\subsection{SCM in RMG Industry}

Lam and Postle (2006) have reviewed the concept of supply chain management in textile and apparel supply chain management in Bangladesh. They discussed the strengths and problems faced by the Bangladesh textile apparel supply chains. They argued that Bangladesh apparel industry is generally not aware of the concept of supply chain management and industrial benchmark for both manufacturing and retailing industries in Bangladesh [2].

Nuruzzaman and Rafiq (2005) took an attempt to develop more effective supply chain for Bangladeshi RMG to enjoy competitive advantage in the global apparel business through analyzing the current supply chain and investigating the relationship among the players in the supply chain. [5]

Islam (2013) analyzed that apparel supply chain matters such as new orders, raw materials supply, production processes and logistics related to finished goods delivery by using efficient supply chain process and also mentioned that Bangladesh garment industry improvement is desired in reducing the supply time required to produce and fulfill the orders placed by foreign companies. His findings is using modern fast and effective machinery can reduce time taken to deliver the order. [2]

Saiful and Noorul (2013) analyzed the approach is to compile the supply chain managementor the Bangladesh garment industry seriously. In the RMG sector the supply chain management is more complex owing to characteristics of global supply chain (SC). In the global supply chain, crossing borders nearby supply with a multiplicity of general obstructions to intercontinental business: tariffs, nontariff obstructions, switch over rates and differences in product necessities, consumer savors and business observes. Borders also present some impediments in transportation services, which are very common for RMG sector in Bangladesh. Manufacturers, suppliers, and buyers all stages of supply chain in the RMG sector are decentralized. Different stages of supply chain have conflicting goals and objectives. [3]

Asgari and Hoque (2013) examined the opportunity that lies in an integrated supply chain to provide a competitive advantage to the Bangladesh RMG sector. A system dynamics approach has been used to identify the dominant variables of 
supply chain performance such as enablers, performance or results, and inhibitors in the RMG sector. Since the end consumers of the apparel fashion market are becoming increasingly time-sensitive, a decrease in lead time, besides quality and cost criteria, is needed to win more orders from buyers. [4]

\section{Methodology}

The information's have been collected on primary as well as on secondary basis. The secondary data were collected from various publications i.e. books, journals, conference papers, annual and audit reports Bangladesh Garment Manufactures \& Exporters Association (BGMEA), different websites etc. On the other hand, interviews of merchandisers of the garments factory were the primary data source.

In this research qualitative method has been used. By using this method how merchandiser think about the garments production flow and total supply chain model are examined which are very relevant to this research.

\section{Process of Garments Manufacturing Industry}

\subsection{Three Decision Level}

Successful supply chain management requires many decisions relating to the flow of information, product, and funds. These decisions fall into three categories or phases, depending on the frequency of each decision and the time frame over which a decision phase has an impact. [7]

a) Strategic Level: Strategic level decisions are the highest level. Strategic level decision concerns general direction, long-term goals, philosophies and values. These decisions are the least structured and most imaginative; they are the most risky and of the most uncertain result, partly because they attain so far into the future and partly because they are of such significance.

b) Planning Level: Planning level decisions support strategic decisions. They tend to be medium range, medium importance, with moderate outcomes. These decisions are tactical planning, and they have a shorter life than level-one decisions. Detailed information is available, and the data probably are very reliable. Level-one decisions constrained these decisions with some flexibility to account for sudden change in data. Quick response is nice to have, and occasionally a requirement at this level. Example: One that needs to commit priority orders and obey commitments made in level one. [2]

c) Operating Level: Operating level decisions are every day decisions, used to support planning level decisions. They are often made with little thought and are structured. Their impact is immediate, short term, short range, and usually low cost. The outcomes of a bad operating level decision will be minimal, although a series of bad or sloppy operating level decisions can cause harm. These decisions. can be pre-programmed, pre-defined, or set out clearly in policy manuals.

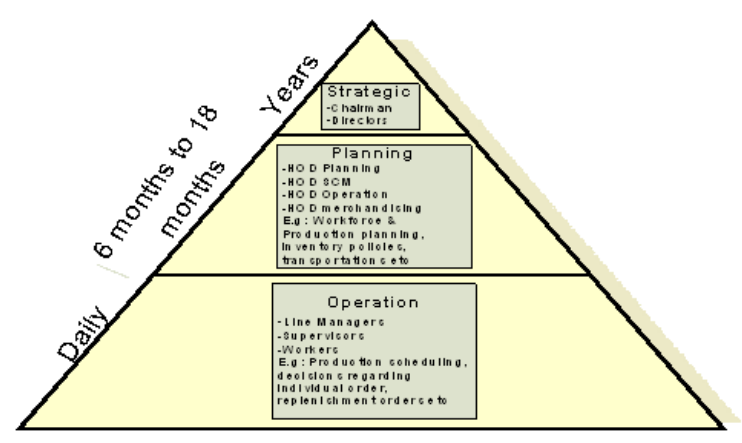

Figure 3. Decision Phase in Supply Chain Management

\subsection{Production Processes in Garment Manufacturing}

Garment manufacturing includes number of processes from order receiving to dispatching shipment of the finished garments. A process flow chart helps to understand how raw materials are moved from one process to another process until raw materials are transformed into the desired product (garments). To be noted that a process flow chart made for the garment manufacturing processes will vary based on manufacturing facility and product types. But here we tried at our best to make a generalized process flow charting which most of the garments following and can be easy to realize for reader of this report. Based on present apparel industry, garment manufacturing processes are categorized a pre-production process, production process and post production process.

\subsubsection{Pre-Production Processes}

Pre- production process includes sampling, sourcing of raw materials, Approvals, PP meeting etc. In pre-production process develop sample as per buyer requirement and also take approval from buyer for bulk production. In this stage, garment factories also source the material from local or international market. [8]

A.Order Receive: Garments manufacturer received Purchase order (PO) from buyer like H\&M, Wal-Mart and other RBO's. All the information's which are required for garment manufacturers are in PO like size, barcode, department name etc.

B.Strategic Planning: In this stage management level working with planning for human labor, building, machineries and material management to ensure the best use of it. In strategic planning level, management team decide how many garments will produce in a certain time period, and how many labor and machines will be use for production.

C.Sample Development: In sample development stage merchandising department working to prepare sample as per artwork provided by the buyer. When sample development completed and merchandising department send the sample to buyer for approval. Different steps i.e. sample development, Pre-production sample, Pre-production sample etc. are related to sample 
development process.

D. Material Sourcing: $\mathrm{n}$ this stage material should be source as per strategic plan from domestic or international market and in-house in warehouse. In perspective of Bangladesh RMG sector most of the procurement will be done from international market. It is one of the most important part for a garment factory.

E. Material In-house: Fabric, Non fabric, trim and other accessories items are in-house or stored as inventory. After material in-house, it will be checked as the physical quantities are matched with booking quantity.

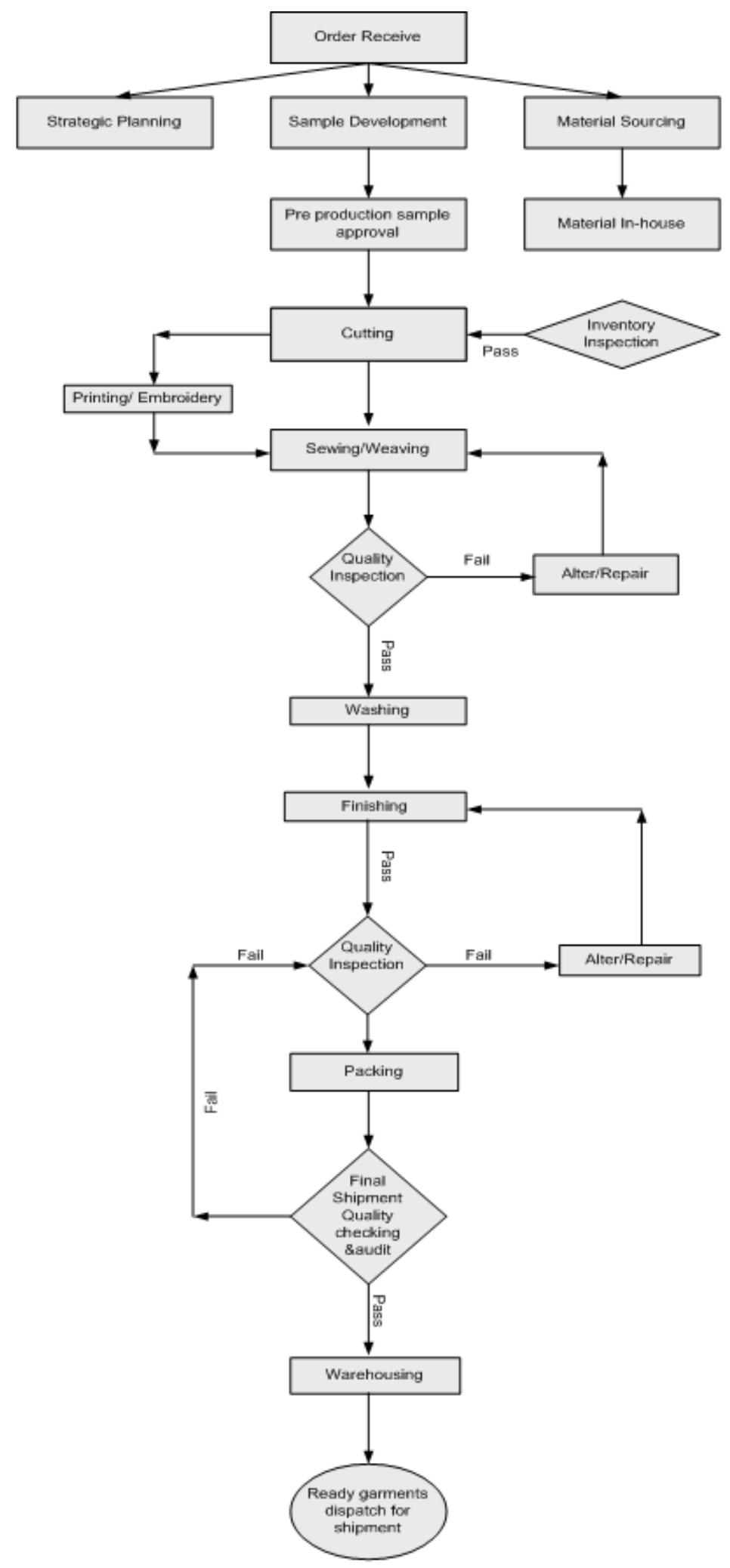

Figure 4. Production flow chart of RMG 


\subsubsection{Production Processes}

Production processes are cutting, sewing, finishing etc. Production process means all the raw materials in your store and you can go for bulk production of garments. So material in-house is the per requisite for starting production [8]

- Cutting: In this stage fabric items are cutting as per garments requirement. Top and bottom part of the garments should be in different cutting process and different types of machines are need for cut the fabric.

- Sewing/Weaving: All the cutting fabrics are sewing in this stage and fix up with each other to produce a full garment. All the sewing process done in the different production line.

- Washing: Washing is one of the vital point for a garment because washing need to soften and maintain the color quality of the products. But some garments do not need washing. At most $80 \%$ percent garment need washing

- Finishing: It is the final stage of production process. In this process all the accessories are sewing or attaching with the garments. In this stage garments are attached with swing item and ready for packing.

\subsubsection{Post Production Processes}

Thread trimming, pressing, checking, folding and packing, shipment inspection on etc are the part of post production process. [9]. mainly thread trimming, packing, warehousing and shipment dispatch process have been done in this step.

(a) Packing: In packing stage, all the garments are packed and finally quality check for shipment. Pressing, checking, folding and packing are the parts of this stage.

(b) Warehousing: Warehouses are basically used by manufacturers, importers, exporters, wholesalers, transport businesses, customs, etc for storage the goods/inventory. In the warehouse all types of raw material, finished goods and accessories items are stored in the warehouse. All the ready garments are send to the central warehouse for shipment.

(c) Shipment Audit: Shipment audit is done by the third party quality checker or buyers direct quality checker which appointed by buyers to check whether all the garments are ready based on PO. This part is mostly crucial part for a garment factory because for shipping the garments, a garment factory must be passed in shipment audit.

(d) Dispatch for Shipment: Inventories which in central warehouse are consecutive dispatched for shipment. Goods can be dispatched by air, train or sea. But in Bangladesh perspective goods shipped by most of time in by sea. In case of emergency goods can be shipped by air to avoid any sort of claim by buyer.

\section{Research Framework/Conceptual Model}

A conceptual model of supply chain of RMG sector of Bangladesh in terms of suppliers, manufacturer, and customers 1 and 2, ultimate buyer are represented in below figure 5. In RMG sector, all the Bangladeshi garment companies are subcontractor. Basically they are performing cutting, making and trimming (CMT) activities. The RMG industry is highly dependent on imported raw material. About $90 \%$ of woven fabrics and $60 \%$ of knit fabrics are imported to make garments for export. Therefore this industry takes maximum lead time to process an order [5]. In Bangladesh, the lead time for apparel export varies between 90-120 days. [2]

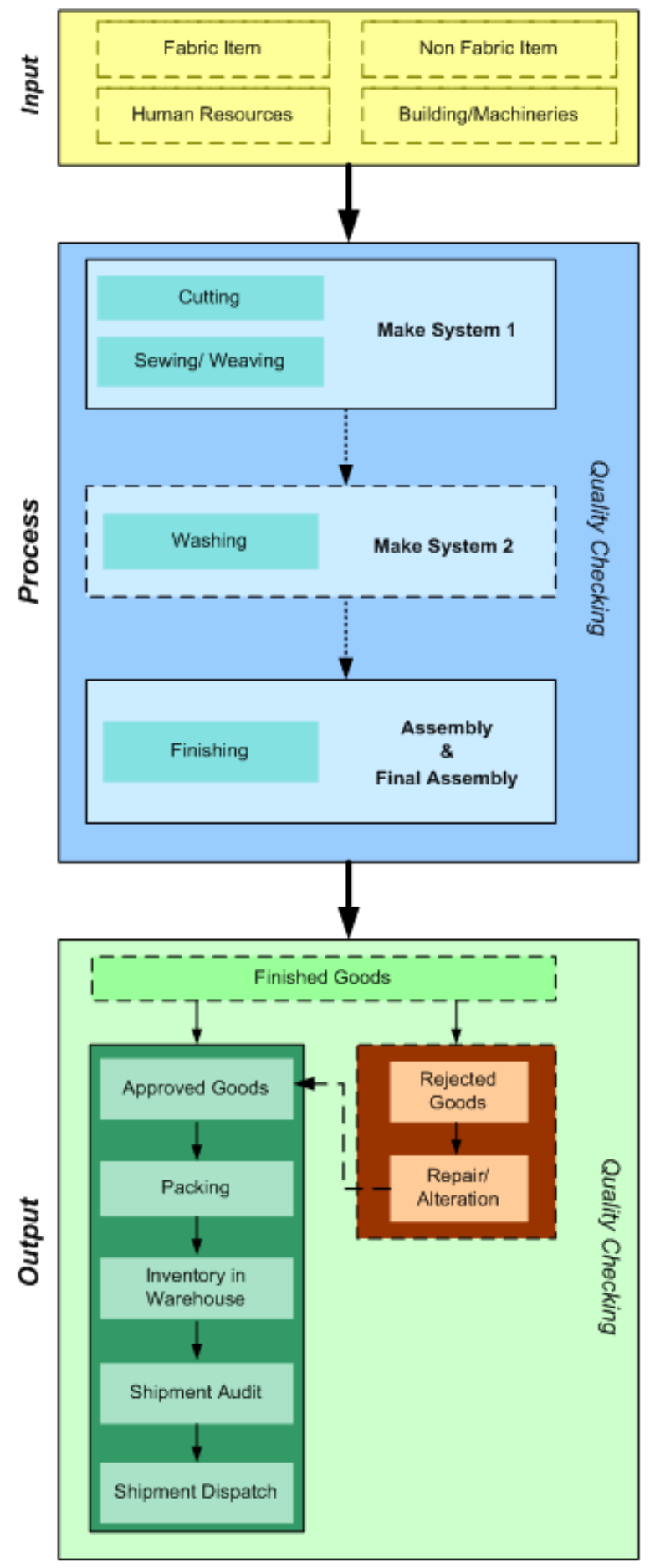

Figure 5. Conceptual framework of SCM in RMG industry of Bangladesh. 
1. Fabric Item: Fabric names in this list include fabrics (woven, non-woven) as well as knitted fabrics, netting fabrics, and technical fabrics (such as Gore-Tex and Gannex). All of the fabric items are in input process because garment production mostly depends on fabric.

2. Non-Fabric Item: There are many non-fabric items which are need for production like chemical, flash spun fabric etc. Non fabric items are accessories and packaging material.

3. Human Resources: Human resources put into input system because it found that human capital need for production of garments.

4. Building \& Machineries: Building and machineries are facilities for RMG sector and it works as an input. Most of the production process need building or machineries and every production process building and machineries are depreciate.

\subsection{Process}

Process is a continuous action, operation, or series of changes taking place in a definite manner. [11] In process system, it found that main mechanism is executed to produce a garment. There are some steps in the process flow.

\subsubsection{Cutting \& Sewing/Make System 1}

In this steps all the fabric item need to cut as per design and sample and sewing it based on approved sample. Most of the time there are three types of garments can be found top, bottom and inner. All of these items can be cut in different process and also use different types of machine for sewing.

\subsubsection{Washing/Make system 2}

In this step when the sewing is complete then most of the item need washing, it is happened most of the cases near about $80 \%$ of the cases. Washing needs for make the fabrics more soft.

\subsubsection{Finishing/Assembly \& Final Assembly}

In this stage all the parts of the garment assemble for making a final goods. There are different types of works are associated in this steps. Every single department works are assembles in this step to produce a garment.

\subsubsection{Quality Checking}

After final assembly, quality inspectors check the garments. If goods are approved then it will pass as finished goods or if it rejected then it will go for alteration/repair. This part is very important for a garment factory because if the quality checking do not maintain the buyer standard then definitely it will be rejected by buyer QC checking.

\subsection{Output}

In the context of RMG sector, output is the amount of goods produced by a garment factory. Output basically means finished goods with good quality or rejected goods. [11]

\subsubsection{Finished Goods}

After quality inspection if the goods are passed by quality inspector then all the goods converted as finished goods like to add swing item and other accessories add with the garment.

\subsubsection{Approved or Rejected Goods}

Approved finished goods ready for packing and reject goods again need alter or repair. Approved or rejected goods depend on different types of criteria which are measures or determine by the buyer.

\subsubsection{Packing}

In this step, all the approved goods packed and ready for final buyer inspection. In this step all the packaging materials can be used.

\subsubsection{Quality Checking}

In this step, buyer QC team or third party QC team designated by buyer check all the packing goods as per buyer guideline. This step is very crucial for a garment factory because if the garment QC pass the quality but rejected by the buyer QC then need to do again alter/repair works. So internal QC check the garments very carefully to pass the quality check of buyer QC.

\subsubsection{Shipment Audit}

Shipment audit is done by the third party quality checker or buyers direct quality checker which appointed by buyers to check whether all the garments are ready based on PO. This part is mostly crucial part for a garment factory because for shipping the garments, a garment factory must be passed in shipment audit.

\subsubsection{Dispatch for Shipment}

If the goods approved by the buyer then all the goods dispatch for shipment. Goods can be shipped by air, sea or train.

\section{Conclusion}

The Readymade Garment Industry is a significant and essential business sector in Bangladesh overall economy. If we look at the RMG export rate from at the beginning from 1980's to 2013's then we can easily understand the evolution of this process. But the SCM process in RMG sector is scattered in perspective of Bangladesh which is lagging behind in the global competition. To be more efficient in the Global apparel industry Bangladesh have to maintain standard SCM procedures. If the Bangladesh readymade garments industry follow the conceptual model which prescribed in this exploratory research then it will be more effective to efficient in the global market. This paper designates further frontiers for prospective researchers as well as practitioners those are involved with Garments Industry.

\section{Acknowledgements}

The authors would like to express their gratitude to $\mathrm{Mr}$. Rashed Nasser, Senior Executive, Customer Services, Avery Denision Bangladesh Ltd. for his encouragement and support towards this research. 


\section{References}

[1] "Export of RMG from Bangladesh", Internet: www.bgmea.com.bd, [Access: 10 July, 2014]

[2] M.S. Islam., "Supply Chain Management on Apparel Order Process: A Case Study in Bangladesh Garment Industry", Asian Journal of Business and Management Sciences, Vol. 2, No. 8, pp. 62-72, 2012.

[3] S. I. Tanvir and N. Muqaddim, "Supply Chain Management Offering the New Paradigm for Bangladesh Garment Industry", Journal of Economics and Sustainable Development, Vol. 4, No. 20, 2013. ISSN: 2222-1700 (Paper) ISSN: 2222-2855 (Online).

[4] B. Asgari and M. A. Hoque "A system dynamics approach to supply chain performance analysis of the ready-made-garment industry in Bangladesh", Ritsumeikan Journal of Asia Pacific Studies, Volume 32, 2013, Japan.

[5] Nuruzzaman, A. Haque and R. Azad, "Is Bangladeshi RMG Sector Fit in the Global Apparel Business? Analyses the Supply Chain Management", the South East Asian Journal of Management, Vol. IV, No.1, April 2010, Indonesia.
[6] N. Md., "Developing Export of RMG products in Bangladesh: Analyzing the Lead time", Management Trends, Vol.4, No.1, P- 1 ,

[7] A. K. M. N. Huda, B. B. Pathik, A. A. Mohib and M. M. Habib, "Structuring Supply Chain Model for JMI Group: A Case Study", in Proceedings of the International Conference on Innovation Driven Supply Chain 2014, Malaysia, 26-28 March 2014. ISBN: 978-983-43522- 2-6.

[8] "Pre-Production Process", Internet: www.onlineclothingstudy.com, [Access: 15 June 2014]

[9] "Post-Production Process", Internet: www.onlineclothingstudy.com, [Access: 23 September 2014]

[10] Internet:www.fabric2fashion.com, [Access: 22 September 2014]

[11] "Bangladeshi RMG Sector:", Internet:www.wikipedia.org, [Access: 23 September 2014]

[12] S. Chopra, P. Meindl, and D.V. Kalra "Supply Chain Management-Strategy, Planning and Operation", Pearson, India, $4^{\text {th }}$ Edition, pp-3-578. ISBN: 978-81-317-3071-3 